\title{
A VISUALIDADE DAS ESCOLAS DE SAMBA NA DÉCADA DE 1930 INOVAÇÃO, TRANSFORMAÇÃO E RECONFIGURAÇÃO
}

\author{
Gabriel da Costa Turano (UERJ)
}

O artigo apresenta a estética das escolas de samba nos anos 30 a partir dos processos culturais construídos de forma híbrida pelos diversos segmentos da sociedade $e$ de acordo com as formas políticas e sociais de três momentos específicos. Entendendo o processo de formação das escolas de samba na festa carnavalesca da cidade do Rio de Janeiro como um conjunto heterogêneo de formas construtoras da cultura popular urbana, destacamos as redes de relacionamento que permeavam os atores sociais em constante troca de influências buscando espaço e representação no carnaval carioca. Destarte, as variações visuais aqui destacadas representam os diversos processos sociais, políticos e culturais que objetivavam transformar o carnaval das escolas de samba em representantes legítimos do carnaval da cidade do Rio de Janeiro a partir da década de 1930.

ESCOLAS DE SAMBA, CARNAVAL, ESTÉTICA, RIO DE JANEIRO, CULTURA POPULAR. 


\section{COMO SE CONTA A HISTÓRIA DAS ESCOLAS DE SAMBA}

Muito se tem escrito sobre o carnaval das escolas de samba da cidade do Rio de Janeiro ${ }^{1}$. A busca da origem dessa manifestação cultural se evidencia na obra de Araújo (2000), por exemplo, e Cabral (1996), que expõem informações sobre as escolas de samba através de documentos retirados de arquivos diversos, evidenciando seu interesse na fixação das "origens" dessas agremiações. ${ }^{2} \mathrm{O}$ levantamento feito

1. Este artigo foi produzido com o apoio de bolsa do CNPq/Projeto Procultura.

2. Os autores citados contribuem com as pesquisas sobre o carnaval das escolas de samba uma vez que grande número de informações que apresentam, retiradas de arquivos, encontra-se atualmente indisponivel ou inexistente. Neste artigo daremos grande significância à obra de Cabral (1996) por considerá-la fundamental para os estudos sobre o carnaval; partimos da análise das construções feitas pelo autor e propomos novas interpretações das fontes utilizadas. A obra de Araújo (2000) que citamos serve a nosso leitor como conhecimento a respeito das obras literárias sobre o carnaval da cidade do Rio de Janeiro. por Cabral caracteriza o desejo de relatar a história do carnaval das escolas de samba e identificar seus personagens, suas histórias, como forma de preservar aquele "mundo" do samba carioca, com suas peculiaridades populares "únicas", "íntegras", o que justifica a valorização das manifestações artísticas das escolas de samba em seu primeiro momento, procurando preservá-las na forma como se encontravam, sem creditar mudanças constantes nessas formas.

É possível encontrar estudos voltados para representantes dos grupos de samba em que a exaltação de alguns personagens evidencia o desejo de resgatar uma memória popular da década de 1930, como os de Silva e Santos (1979), sobre a participação de Paulo da Portela nos anos iniciais das escolas de samba, e Silva e Oliveira Filho (2008), uma biografia de Cartola.

Eneida de Moraes (1987) procurou organizar as manifestações carnavalescas da cidade, determinando quais seriam suas principais manifestações nos anos 50. Hermano Vianna (1995) caracteriza o movimento do samba na década de 1930 como fenômeno da cultura nacional atrelado ao conceito de brasilidade que permeava a intelectualidade dos anos 20 e 30. Tratando das escolas de samba, Felipe Ferreira (2004) informa sobre sua ascensão em consonância com o movimento modernista da década de 1920 e início da seguinte, quando a busca de manifestações populares no período carnavalesco passou a vigorar entre os pensadores e financiadores do carnaval carioca. Valéria Guimarães (2009) propõe análise da participação das escolas de samba junto ao PCB na década de 1940, levantando ques-

tões como a construção de uma cultura popular através da interferência dos membros de uma elite do país numa relação de negociação com os grupos populares, delimitando as classes, de forma a identificar cada grupo da sociedade.

Ao estudar as escolas de samba deparamo-nos com o conceito de cultura popular que, durante alguns anos, se caracterizou por representações folclóricas ou simplistas no entendimento das relações de sua construção. 
Ferreira (2005) apresenta panorama das festividades carnavalescas na cidade do Rio de Janeiro do século XIX e início do seguinte, e, mais do que simplesmente contar a história dessa festa ou situá-la como representação cultural pronta e de elaboração homogênea, visa entendê-la e identificá-la através da teoria ator-rede na qual destaca a construção de redes sociais mediante as relações entre objetos e sujeitos (atores) em constante busca de estruturas estáveis.

Sobre as redes e suas estruturas informa o autor que

se organizam em dois tipos principais: as redes estabilizadas, em que um elemento central determina as relações por meio de normatizações; e as redes instáveis, em que os padrões estão sendo constantemente negociados. Nos dois casos, entretanto, a organização gera ininterruptamente (em graus diferentes, de acordo com o caso) incertezas, ambivalências, transgressões e resistências e, portanto, uma contínua renovação (FERREIRA, 2005, p. 22).

Procuramos entender as construções sociais através dos grupos em constante negociação estruturando redes ora estáveis, ora instáveis articuladas aos processos de formação do carnaval das escolas de samba na década de 1930 destacando os aspectos visuais vinculados a tais processos.

Canclini (2008), trabalhando com o conceito de hibridismo, procura entender as relações sociais de forma complexa, com diversos atores sociais interagindo, misturandose, negociando, e, desde sempre, formando identidades que não são fixas, mas, ao contrário, estão em constante fluidez.

Fazendo uma análise da cultura popular, erudita e de massa o autor acredita que as formas culturais se originam de fusões conflituosas. A hibridação se define então por "processos culturais nos quais estruturas ou práticas discretas, que existiam de forma separada, se combinam para gerar novas estruturas, objetos e práticas" (p. 19). Nesse sentido as relações de hibridação na festa carnavalesca se traduzem nos processos de trocas culturais entre os grupos da sociedade carioca, em que os sambistas com suas práticas individuais ou coletivas dialogam com os membros das elites e do governo, dando origem a novos textos e práticas, como as escolas de samba com seus desfiles, instrumentos, apresentações, indumentárias, alegorias, enredos etc.

Destacamos ainda que os textos e práticas da cultura popular estão em movimento, são dinâmicos, formados por contradição produzida por diversas forças sociais, e que a festa carnavalesca é o terreno das trocas e negociações entre a cultura do povo e a cultura dominante (STOREY, 2009, p. 10).

A cultura popular, as escolas de samba incluídas, parafraseando Hall (2006, p. 232) não é tradição popular de resistência aos processos modernizadores ou dominantes, nem mesmo uma forma que a eles se sobrepõe, sendo antes o terreno sobre o qual as transformações são operadas. É preciso entender a cultura popular a partir das relações constantes com as instituições da produção cultural para dessa forma percebermos as apresentações das escolas de samba e suas especificidades estéticas na década de 1930. 


\section{AS ESCOLAS DE SAMBA E OS JORNAIS (1932-1934)}

Dividindo o carnaval das escolas de samba em três momentos, interligados entre si e deixando de lado a questão do aparecimento das escolas de samba no carnaval da cidade do Rio de Janeiro, bem como os momentos políticos, sociais e culturais da década de 1920, voltamo-nos prioritariamente para seu primeiro desfile, - no primeiro contexto por nós identificado (1932-1934) -, promovido em 1932 pelo jor-

3. Entende-se, nesse contexto, por elite intelectual os fomentadores da festa carnavalesca das escolas de samba, que as apoiavam recebendo-as em suas redações e promovendo o concurso entre ela. Em 1932 os representantes da elite intelectual que apoiaram as escolas de samba foram os jornais Mundo Esportivo (criador do primeiro concurso das escolas de samba) e O Globo (que noticiou as atividades promovidas pelo Mundo Esportivo). nal Mundo Esportivo, ${ }^{3}$ que pertencia a Mário Filho, tendo como colaboradores Orestes Barbosa, Nássara e Cristóvão de Alencar, ficando o contato com as escolas de samba a cargo do repórter Carlos Pimentel.

O jornal O Globo (3 de fevereiro de 1932, p. 7), durante os quatro dias que antecederam a festa, informou como seria o inédito concurso das escolas de samba realizado pelo Mundo Esportivo, destacando a nova diversão carnavalesca da cidade com características próprias, como o concurso de melodias de sambas, o malandro e sua capacidade de improvisação, a participação das melhores escolas de melodia, com o uso de instrumentos que a população da cidade não conhecia, além da valorização dos morros e ladeiras.

O destaque do primeiro concurso permeou a manifestação cultural popular, inovadora, pura, intocada, original, prevalecendo em seu aspecto visual a simplicidade, sem fantasias luxuosas. Esperava-se das escolas de samba, no primeiro concurso a elas destinado, o desempenho musical e rítmico, muito mais do que alegórico. $O$ interesse não consistia nos desfiles, como dos ranchos, blocos e grandes sociedades, revelando-se antes no desejo de festejar um novo ritmo musical, sem a necessidade latente de indumentária.

No Carnaval de 1933, dois foram os desfiles das escolas de samba, embora o registro na bibliografia carnavalesca informe a organização do carnaval das escolas de samba por parte do jornal $O$ Globo, que formula regulamento proibindo instrumentos de sopro e estabelecendo a obrigatoriedade da ala de baianas. Alguns quesitos passaram a constar no regulamento para a melhor orientação dos jurados. Note-se a participação da elite intelectual na construção do carnaval das escolas de samba através de orientações para melhor apresentar o desfile, com a proibição de instrumentos de sopro, presentes nas rodas de "choro" da cidade, por exemplo, além da obrigatoriedade da ala das baianas, representantes do passado africano. Ainda segundo esse regulamento elaborado por O Globo (25 de fevereiro de 1933, p. 4), as escolas de samba deveriam ser julgadas respeitando-se os seguintes quesitos: harmonia, poesia do samba, enredo, originalidade e conjunto. Note-se também a valorização, via os três primeiros quesitos em julgamento, do samba como representante musical popular dos moradores dos morros. A 
questão visual, grandemente explorada pelas grandes sociedades e ranchos através de fantasias e carros alegóricos, por exemplo, não é alvo de interesse com relação às escolas de samba, apesar de destacarem-se nos quesitos a "originalidade" e o "conjunto" de cada agremiação. A visualidade "original" das escolas de samba desse segundo ano de desfile, 1933, não é o fator determinante de sua diferenciação dos demais grupos carnavalescos da cidade.

Em 1934, segundo Cabral (1996), uma grande festa em homenagem ao prefeito Pedro Ernesto antecipou o carnaval da cidade para o dia 20 de janeiro. De acordo com Silva e Santos (1979) o primeiro evento "oficial" carnavalesco de 1934 ocorreu em 20 de janeiro, dia do padroeiro da cidade, São Sebastião, com o intuito de homenagear o prefeito Pedro Ernesto por suas benfeitorias ao carnaval da cidade. O desfile das escolas de samba aconteceu juntamente com a apresentação das grandes sociedades, ranchos e blocos, além do Cordão do Bola Preta. Todos "misturados", apresentavam-se sob a chuva que caía, sendo as escolas de samba classificadas pela comissão julgadora constituída pelos jornalistas Francisco Neto, Floriano Rosa Faria, Jota Efegê, Venerando da Graça e Antônio Veloso. E passam então a figurar entre os representantes do carnaval carioca, desfilando com os demais grupos, apesar das diferenças estéticas.

Na classificação das escolas de samba a Estação Primeira recebeu o primeiro lugar, e a comissão julgadora destacou seu samba, de grande efeito e ritmo vocal. O segundo lugar ficou com a Vai Como Pode (Portela) que, segundo os jurados, se apresentou com a forma característica de escola de samba (O Paíz, 23 de janeiro de 1934, p. 8), comentário que merece atenção especial, pois define o que esperar de uma escola de samba. Informa também que as demais escolas que desfilaram no Campo de Santana não apresentaram o suficiente para ser consideradas plenamente escolas de samba. Contudo, apesar dessa ressalva, a campeã foi a Estação Primeira em função de seu samba.

Os três primeiros desfiles das escolas de samba, elaborados através de redes de relacionamento entre a elite intelectual e financeira da cidade e as escolas de samba, demonstram o caráter de busca de nova forma para o carnaval da cidade, em que o folclórico, o popular, a música, intocada pelas próprias elites, formariam o objeto central dessa construção.

\section{AS ESCOLAS DE SAMBA E A UES (1935-1937)}

A criação da União das Escolas de Samba - UES em meados de 1934 e o constante diálogo entre os grupos, a institucionalização de práticas, tornada comum entre os integrantes das escolas de samba, fizeram surgir em 1935 uma tradição das escolas de samba, incentivada pelos discursos nacionalistas dos jornais da cidade.

Tratando de organizar o desfile de 1935, A Nação e a UES elaboram regulamento capaz de desenvolver mecanismos específicos de orientação para a forma de apresentação das escolas de samba. Simultaneamente a definição traz à tona todo um conjunto estético e contém uma determinada história sobre como e onde essa expressão cultural sustenta suas origens. $O$ regulamento acentuava, por exemplo, que só as escolas filiadas 
à UES poderiam apresentar-se no desfile, diferentemente de anos anteriores; informava a proibição do uso de instrumentos de sopro, além de determinar os 15 minutos para o desfile de cada escola de samba. A busca de padrões de conduta, apresentação, vestimenta, utilização de instrumentos e enredos evidencia a importância dos itens que circundam as manifestações culturais e salientam suas especificidades.

O resultado do desfile das escolas de samba de 1935 não agradou a muitas escolas. Cabral (1996, p. 104) informa que até um dos jurados, Ismael Silva, discordou do resultado aplicado pela comissão julgadora. A falta de organização no desfile das escolas de samba foi repercutida nos jornais da cidade. O Diário Carioca (10 de março de 1935, p. 15), recebendo visita de João Hilário dos Santos Mattos, presidente da escola de samba Unidos do Tuiuti, colhe seu depoimento e publica entrevista em que ele faz críticas ao carnaval das escolas de samba daquele ano, afirmando que o concurso fugiu a todas as regras estabelecidas. Segundo sua declaração, ficara proibida a utilização de pastas, cartonagem, instrumentos de sopro, carros alegóricos, estandartes, e todas as proibições foram descumpridas por algumas escolas de samba. Ao narrar o descumprimento das obrigatoriedades estabelecidas pela UES e pelo jornal $A$ Nação, aponta que as escolas de samba transformaram suas formas de apresentação modificando a estética de seus componentes. Nesse ano, algumas escolas de samba desfilaram com carros alegóricos, instrumentos de sopro e estandartes, diferença consistente com relação aos três primeiros anos do concurso.

Falando a respeito do desfile das escolas de samba no Carnaval de 1936 o Diário Carioca (23 de fevereiro de 1936) informa o regulamento a ser seguido pelas escolas de samba naquele ano e afirma que ele só foi divulgado no dia do desfile, algo diferente do que ocorrera nos anos anteriores. Acrescenta que as escolas de samba deveriam cantar dois sambas-enredo em 15 minutos de desfile, no qual não seria permitido o uso de instrumentos de corda nem de sopro. As escolas de samba seriam julgadas e classificadas pela maior quantidade de pontos que conseguissem fazer na soma das avaliações de harmonia, samba, bateria, bandeira e enredo. O regulamento elaborado pela UES é acrescido de uma somatória para a classificação das escolas de samba, levando-se em consideração quesitos específicos. Não se proíbem carros alegóricos, luxo nas fantasias, fogos de artifício nem tema estrangeiro. Há flexibilidade na construção desse regulamento, o que gerará críticas ao resultado.

Segundo Cabral (1996, p. 380) a Unidos da Tijuca ficou em primeiro lugar, tendo a Estação Primeira alcançado a segunda colocação, a Portela o terceiro lugar, a Depois Eu Digo o quarto, a Deixa Malhar o quinto, e a Vizinha Faladeira o sexto. $O$ autor afirma que: "Para o jornal $A$ Nação, a decisão mais justa teria sido a de dar à Estação Primeira o primeiro lugar, à Vizinha Faladeira o segundo e à Portela o terceiro" (p. 110). Silva e Santos $(1979$, p. 106) informam que o jornal A Rua estabeleceu julgamento extraoficial que classificou a Portela em primeiro lugar, a Estação Primeira em segundo e a Vizinha Faladeira na terceira colocação. $O$ desencontro de opiniões a respeito do concurso das escolas de samba, por parte da elite intelectual, denota movimento de "oposição" aos atos direcio- 
nados pela UES, e pelas escolas de samba, que, cada vez mais se preocupavam com apresentações capazes de chamar a atenção do público carioca para a Praça Onze nos dias de carnaval.

O luxo entre as escolas de samba é afirmado pelo jornal $A$ Noite (24 de fevereiro de 1936, p. 1), que destaca Vizinha Faladeira, Estação Primeira, Salgueiro, Portela e outras como representantes das novidades no carnaval das escolas de samba. A nota de luxo registrada em A Noite também é repetida por O Radical (3 de março de 1936) quando faz críticas ao concurso das escolas de samba organizado pela UES. Segundo o jornal a comissão julgadora era composta de leigos nos temas carnavalescos e foi inapropriada a forma de condução do julgamento e reconhecimento de valor das escolas de samba.

Com relação a 1937, é possível destacar o interesse pelas escolas de samba, por sua produção artística, posto que se haviam transformado em representantes do nacionalismo brasileiro, da cultura brasileira. A cada ano, novos atores aparecem e, participando ativamente de diálogos com as escolas de samba, tecem novas formas de visibilidade e estimulam as apresentações dos sambistas na cidade.

Segundo o Diário de Notícias (9 de fevereiro de 1937), ranchos e blocos já não gozavam de tanto prestígio carnavalesco como as escolas de samba, que haviam evoluído e mudado a partir do contato com a cidade, com seus grupos, propiciando a inclusão de carros alegóricos e comissões de frente a cavalo no desfile de carnaval.

Com o enredo "A Origem do Samba" a Vizinha Faladeira se destaca das demais escolas no Carnaval de 1937. Com alegorias e adereços capazes de aguentar a forte chuva que desabou no carnaval, a escola inovou ao utilizar instrumentos de sopro em seu desfile. Segundo Cabral (1996, p. 113), "naquele ano, o regulamento do desfile eliminou a proibição do uso de instrumentos de sopro e não apresentou qualquer restrição à utilização do automóvel e dos cavalos"..

No Carnaval de 1937, em virtude de ordenação do segundo delegado auxiliar Dulcídio Gonçalves para encerrar o desfile, apenas 15, das 32 escolas de samba desfilaram na Praça Onze, incluindo-se a Vizinha Faladeira, a Portela e a Azul e Branco. Ficaram fora do concurso escolas de samba como Unidos da Tijuca, Estação Primeira e Prazer da Serrinha.

A Vizinha Faladeira é eleita campeã com o total de 187 pontos. Em segundo lugar se classifica a Portela, com 175 pontos, e em terceiro a Depois Eu Digo. O Radical (12 de fevereiro de 1937) informa que a comissão julgadora fez referência especial à escola de samba Portela informando que ela foi a única a se apresentar como uma verdadeira escola de samba ao conservar as tradições. $O$ Radical ao exaltar a escola de samba Portela informa que as demais escolas de samba não se portaram como escolas de samba, mas antes, tentavam se igualar a blocos e ranchos, destacando nesse sentido a campeã Vizinha Faladeira, que apresentou comissão de frente com cavalos.

Se para a UES não existe problema na utilização de carros alegóricos e comissões com cavalos, outros grupos, como a elite intelectual, não compartilham da mesma direção de construção do carnaval das escolas de samba. Indicando o caminho a ser segui- 
do, a comissão julgadora composta de cronistas carnavalescos e de um representante do turismo carioca, aponta para a retomada da simplicidade, da pureza e da brasilidade no conjunto das escolas de samba, algo perdido com o estabelecimento da UES e a centralização da organização das atividades das escolas de samba no período 1935-1937. Dessa forma, os cronistas carnavalescos, as elites, e o próprio Governo de Vargas, a partir de 1939 , identificam as escolas de samba através de suas fantasias simples, pelas baianas, pelas cuícas, pandeiros e tambores, além do canto das pastoras e das danças, e menos pelos carros alegóricos, fogos, fantasias luxuosas etc.

\section{MUDANÇAS LATENTES (1938-1940)}

É comum informar a ausência de jurados no concurso das escolas de samba de 1938 devido à chuva que assolou a cidade (CABRAL, 1996) e (SILVA; SANTOS, 1979). O desfile das escolas de samba aconteceu, apesar de não haver classificação, ficando as agremiações prejudicadas devido aos investimentos feitos para aquele carnaval.

Segundo Silva e Santos (1979, p.110), em 1938 houve mudanças no regulamento das escolas de samba com o intuito de melhor apresentá-las ao público, evitando os "exageros" cometidos pela campeã do carnaval do ano anterior. Fez-se valer a proibição do uso de carros alegóricos ou carretas, da mesma forma como não se poderiam utilizar temas internacionais na composição dos enredos. O julgamento avaliaria o samba, a harmonia, a bandeira, o enredo, a indumentária, a comissão de frente, a fantasia do mestre-sala e da porta-bandeira, e a iluminação da escola. O samba retorna ao foco da apresentação, incluindo-se a indumentária, retirando-se o carnaval espetacular das escolas de samba.

A utilização de enredos nacionais parece indicar o caminho da mudança política experimentada pelo país e pelas escolas de samba com a implantação do governo ditatorial (1937-1945). As transformações políticas ocorridas no Brasil, com destaque no Rio de Janeiro, não impediram as escolas de samba de se adaptar aos novos grupos capazes de organizar e elevar o carnaval das escolas de samba a novo status.

Produzir eventos de caráter nacionalista, após a implantação do Estado Novo tornou-se algo comum na cidade do Rio de Janeiro. A exaltação de ranchos, blocos e escolas de samba faz parte do projeto de imbuir o carnaval de manifestações tipicamente populares, de destaque da cultura popular brasileira. Contando com o interesse das elites da cidade, intelectual e financeira, a burguesia carioca experimenta um momento de consu-

4. Logo no início de 1939 a UES atravessa uma crise e em assembleia geral seus representantes mudam 0 nome da instituição para União Geral das Escolas de Samba - Uges, escoIhendo Antenor dos Santos para a Presidência. mo cultural nacional em grande escala, constituindo as escolas de samba o maior representante desse objeto cultural.

O regulamento de 1939 não foi aprovado pela Comissão responsável da União Geral das Escolas de Samba - Uges. ${ }^{4}$ Buscando resolver o impasse, seus integrantes acrescentam ao regulamento de 1938 os quesitos a serem julgados, os prêmios e a obrigatoriedade de entregar os enredos com antecedência. Não se apresenta a proibição de instrumentos de sopro, carros ale- 
góricos ou temas estrangeiros, itens que, contudo, haviam sido proibidos no regulamento de 1938, em que não houve julgamento devido à ausência dos jurados. O regulamento foi noticiado 17 dias antes do desfile das escolas de samba no domingo de carnaval, dando-lhes menos de um mês para se organizarem para os festejos de Momo.

A falta de organização de acordo com o regulamento de 1939 transparece nas escolas de samba com apresentações diversas, contando com carros alegóricos, fantasias luxuosas e compostas de inovações.

O desfile das escolas de samba foi realizado na Praça Onze tendo como jurados Lauro Alves de Souza, Atheneu Glasser, Lourival César, Álvaro Pinto da Silva e Austregésilo de Ataíde que sagraram a Portela a escola de samba campeã de 1939, com o enredo "Teste do Samba". Cabral (1996, p. 125) informa "que a comissão julgadora aplicou, pela primeira vez, o dispositivo que proibia a abordagem de temas estrangeiros nos enredos e desclassificou a Vizinha Faladeira". A exclusão da Vizinha Faladeira revela os diversos atores da sociedade e seus diálogos tensionados na construção de um carnaval cada vez mais popular, um carnaval verdadeiramente nacional, representante do povo, com características de folclore nacional, exaltando-se a bandeira, as cores brasileiras, os militares, a fauna e a flora. Algumas escolas de samba, assim como a Uges, perceberam o novo processo em construção no carnaval das escolas de samba, uma mudança latente, da qual a Vizinha Faladeira não participará.

A Segunda Guerra Mundial iniciada em setembro de 1939 e a ditadura do Estado Novo modificam o cenário carnavalesco do Rio de Janeiro em 1940. Se antes as manifestações populares se aclimatavam com grupos representantes da esquerda brasileira, como o prefeito Pedro Ernesto, a partir da instauração do governo ditatorial (1937-1945) o cenário político e cultural se modifica, de forma lenta até 1939 e se acelerando com o início de 1940. O poder público passa a regular com mais intensidade o carnaval das escolas de samba mediante atos simples, mas que representam a presença desses agentes políticos junto aos grupos populares. O resultado desse processo de interações sociais e culturais dos diversos grupos da sociedade carioca com as escolas de samba são diálogos que aos poucos modificam as formas de sua apresentação.

O desfile de 1940 ocorreu do dia 4 de fevereiro, domingo de carnaval, na Praça Onze, com comissão julgadora indicada pelo prefeito da cidade, Henrique Dodsworth, e composta pelos seguintes jurados: Modestino Kanto, Francisco Guimarães Ribeiro, Gehardt Luckmann, funcionários da prefeitura, além de Arlindo Cardoso e Lourival Dalier Pereira, cronistas que gozavam de prestígio junto à municipalidade. Trinta escolas de samba desfilaram então, embora apenas 23 tenham sido julgadas - as filiadas.

Outro estado carnavalesco estava sendo criado, com novas propostas, em que as escolas de samba também se incluíam no ato de fazer o carnaval. Deveriam dar sua contribuição ao movimento cada vez mais nacionalista instaurado pelo Estado Novo revendo suas propostas artísticas e estéticas de meados da década de 1930. Do primeiro momento (1932-1934) marcado pela busca da pureza, exaltando a música popular, passando pelo segundo período (1935-1937), no qual as escolas de samba se autoafirmam no car- 
naval, através da UES e das práticas institucionalizadas; culminando com o terceiro período (1938-1940), em que se vê a transformação das relações políticas, culturais e sociais entre escolas de samba, elites e governo, percebe-se que o carnaval das escolas de samba ao longo da década de 1930, bem como a cultura popular carioca de modo geral, foi construído através de constantes diálogos que vão conduzir a modificações nas formas estéticas de apresentação das escolas de samba.

A cultura popular das escolas de samba é, nesse sentido, constantemente recriada através das interações sociais, que não se impõem umas às outras, mas, ao contrário, negociam constantemente seus interesses e estabelecem padrões culturais desejados pela sociedade. As escolas de samba são híbridas, e sua estética representa cada momento político cultural por elas enfrentado.

\section{REFERÊNCIAS BIBLIOGRÁFICAS}

ARAÚJO, Hiram. Carnaval: seis milênios de história. Rio de Janeiro: Griphus, 2000.

CABRAL, Sérgio. As escolas de samba do Rio de Janeiro. Rio de Janeiro: Lumiar Editora. 1996.

As escolas de samba: o quê, quem, como, quando e por quê. Rio de Janeiro: Fontana, 1974.

CANCLÍNI, Néstor García. Culturas híbridas: estratégias para entrar e sair da modernidade. São Paulo: Edusp, 2008.

FERREIRA, Felipe. Inventando carnavais: o surgimento do carnaval carioca no século XIX e outras questões carnavalescas. Rio de Janeiro: Editora UFRJ, 2005.

. O Livro de Ouro do carnaval brasileiro. Rio de Janeiro: Ediouro, 2004.

GUIMARÃES, Valéria Lima. O PCB cai no samba: os comunistas e a cultura popular 19451950. Rio de Janeiro: Arquivo Público do Estado do Rio de Janeiro, 2009.

HALL, Stuart. A identidade cultural na pós-modernidade. Rio de Janeiro: Dp\&A, 2006.

MORAES, Eneida de. História do carnaval carioca. Rio de Janeiro: Record, 1987.

STOREY, John. Cultural theory and popular culture: an introduction. Essex: Pearson Educational Limited, 2009.

SILVA, Marília Trindade Barboza da; OLIVEIRA FILHO, Arthur L. de. Cartola, os tempos idos. Rio de Janeiro: Gryphus, 2008.

SILVA, Marília T. Barbosa; SANTOS, Lygia. Paulo da Portela: traço de união entre duas culturas. Rio de Janeiro: Funarte, Instituto Nacional de Música, Divisão de Música Popular, 1979.

VIANNA, Hermano. O mistério do samba. Rio de Janeiro: Jorge Zahar/Editora UFRJ, 1995.

Gabriel da Costa Turano é mestrando em Artes no Programa de Pós-graduação em Artes da UERJ e formado em História (licenciatura e bacharelado) pela Universidade Gama Filho. 